\title{
Some Separation Properties of the Digital Line
}

\author{
Nirmala Mariappan \\ Department of Mathematics \\ Lady Doak College, Madurai \\ Tamilnadu, India
}

\author{
M. Lellis Thivagar \\ Department of Mathematics \\ Madurai Kamaraj University \\ Madurai, Tamilnadu, India
}

\begin{abstract}
This paper deals with some separation properties of the digital line, semi-regularity, semi-normality, $\mathrm{T}_{\mathrm{b}}$ separation and $\alpha \mathrm{T}_{\mathrm{b}}$ separation of the digital line.
\end{abstract}

\section{Key words and phrases:}

digital line, semi-open sets, g-closed sets,

$\omega$-closed sets, $\alpha \hat{g}$-closed sets, semi-regular space, seminormal space.

\section{INTRODUCTION}

Levine [15], Mashhour et al [18] and Njastad [21] introduced semi-open sets, preopen sets and $\alpha$ open sets respectively. Levine [16] introduced g-closed sets and studied their most fundamental properties. P.Bhattacharya and B.K.Lahiri [3], S.P.Arya and T.Nour [2], H.Maki et al [19] introduced sgclosed sets, gs-closed sets, $\alpha$ g-closed sets and g $\alpha$-closed sets respectively. P.Sundaram and M.Sheik John [24] introduced and studied $\omega$-closed sets.

A characterization of semi-open sets in the digital line is given in this paper. Some separation properties of the digital line are also studied.

\section{SOME SEPARATION PROPERTIES OF $(Z, \kappa)$}

The digital line or so called the Khalimsky line is the set of integers $\mathrm{Z}$, equipped with the topology $\kappa$ generated by $\{\{2 \mathrm{~m}-1,2 \mathrm{~m}, 2 \mathrm{~m}+1\} / \mathrm{m} \in \mathrm{Z}\}$. The concept of the digital line $(Z, K)$ is initiated by Khalimsky [10],[11]. This topological space is denoted by $(Z, K)$. In $(Z, K)$ each singleton $\{2 n\}$ is closed and each singleton $\{2 n+1\}$ is open where $n \in Z$. If $\mathrm{U}(\mathrm{x})$ is the smallest open set containing $\mathrm{x}$, then $\mathrm{U}(2 \mathrm{~m})=$ $\{2 m-1,2 m, 2 m+1\}$ and $U(2 m+1)=\{2 m+1\}$ where $m \in Z$. It is well known that $(Z, K)$ is $T_{1 / 2}$ and $T_{3 / 4}$ but it is not $T_{1}$. In the present section, the semi-regulality and semi-normality of the digital line are proved and so an alternative proof of $[8$, Theorem B] is given. Theorem B [8] shows the digital line is s-normal.

Lemma 2.1 ([14], lines 12-13 in page 175)
For a subset $A$ of $(Z, \kappa)$ to be open it is necessary and sufficient that $2 \mathrm{~m} \pm 1 \in \mathrm{A}$ whenever $2 \mathrm{~m} \in \mathrm{A}$.

Proof Necessity. Let $2 \mathrm{~m} \in$ A. Since A is open, $U(2 \mathrm{~m})=$ $\{2 \mathrm{~m}-1,2 \mathrm{~m}, 2 \mathrm{~m}+1\} \subseteq \mathrm{A}$. Sufficiency. To prove that $\mathrm{A}=$ $\operatorname{int}(\mathrm{A})$. Let $\mathrm{x} \in \mathrm{A}$. Case $1 . \mathrm{x}=2 \mathrm{~m}$. By the hypothesis $2 \mathrm{~m}$ $\pm 1 \in \mathrm{A}$ and therefore $\mathrm{U}(2 \mathrm{~m}) \subseteq \mathrm{A}$. This implies $\mathrm{x} \in$ $\operatorname{int}(\mathrm{A})$. Case 2.

$x=2 m+1$. Since $\{2 m+1\}$ is an open subset of $Z, x \in$ $\operatorname{int}(\mathrm{A})$.

\section{Lemma 2.2}

A subset $A$ of $(Z, K)$ is not closed if and only if there exists $2 \mathrm{~m}+1 \in \mathrm{A}$ such that $2 \mathrm{~m}$ or $2 \mathrm{~m}+2 \notin \mathrm{A}$.

Proof Necessity. A is not closed implies $A^{c}$ is not open. Therefore, by Lemma 2.1, there exists $2 \mathrm{~m} \in \mathrm{A}^{\mathrm{c}}$ such that $2 \mathrm{~m}+1$ or $2 \mathrm{~m}-1 \notin \mathrm{A}^{\mathrm{c}}$. Case $1.2 \mathrm{~m}+1 \notin \mathrm{A}^{\mathrm{c}}$. Then $2 \mathrm{~m}+1 \in \mathrm{A}$ and $2 \mathrm{~m} \notin \mathrm{A}$. Case 2 . $2 \mathrm{~m}-1 \notin \mathrm{A}^{\mathrm{c}}$. Then $2 \mathrm{~m}-1 \in \mathrm{A}$ and $2 \mathrm{~m} \notin$ A. Thus there exists $2 \mathrm{~m}+1 \in \mathrm{A}$ such that $2 \mathrm{~m}$ or $2 \mathrm{~m}+2 \notin \mathrm{A}$.

Sufficiency. Let there exist $2 \mathrm{~m}+1 \in \mathrm{A}$ such that $2 \mathrm{~m}$ or $2 \mathrm{~m}+2$ $\notin \mathrm{A}$. Then $2 \mathrm{~m}$ or $2 \mathrm{~m}+2 \in \mathrm{A}^{\mathrm{c}}$ and $2 \mathrm{~m}+1 \notin \mathrm{A}^{\mathrm{c}}$. Therefore by Lemma $2.1, \mathrm{~A}^{\mathrm{c}}$ is not open and hence $\mathrm{A}$ is not closed.

\section{Theorem 2.3}

A subset $A$ of $(Z, K)$ is semi-closed if and only if $2 n-1$ or $2 \mathrm{n}+1 \notin \mathrm{A}$ whenever $2 \mathrm{n} \notin \mathrm{A}$.

Proof Necessity. Let $\mathrm{A} \subseteq \mathrm{Z}$ be semi-closed and $2 \mathrm{n} \notin \mathrm{A}$. Suppose $2 \mathrm{n}-1$ and $2 \mathrm{n}+1 \in \mathrm{A}$.

Then $\operatorname{cl}(\{2 \mathrm{n}-1,2 \mathrm{n}+1\}) \subseteq \operatorname{cl}(\mathrm{A})$. This implies int(cl( $\{2 \mathrm{n}-1$, $2 \mathrm{n}+1\})) \subseteq \operatorname{int}(\mathrm{cl}((\mathrm{A})) \subseteq \mathrm{A}$. That is $\{2 \mathrm{n}-1,2 \mathrm{n}, 2 \mathrm{n}+1\} \subseteq \mathrm{A}$, which implies $2 \mathrm{n} \in \mathrm{A}$, a contradiction. Sufficiency. To prove that $A \supseteq \operatorname{int}(\operatorname{cl}(A))$. Let $x \in \operatorname{int}(\operatorname{cl}(A))$.

Case 1. $x=2 m+1 . x \in \operatorname{int}(\operatorname{cl}(A)) \subseteq \operatorname{cl}(A)$. Since $\{x\}$ is open, $\mathrm{x} \in \mathrm{A}$.

Case 2. $\mathrm{x}=2 \mathrm{~m} . \mathrm{x} \in \operatorname{int}(\mathrm{cl}(\mathrm{A}))$ implies

$\{2 \mathrm{~m}-1,2 \mathrm{~m}, 2 \mathrm{~m}+1\} \subseteq \operatorname{cl}(\mathrm{A})$. Since $\{2 \mathrm{~m}-1\}$ and $\{2 \mathrm{~m}+1\}$ are open, $2 \mathrm{~m}-1$ and $2 \mathrm{~m}+1 \in \mathrm{A}$. Then, by assumption $2 \mathrm{~m} \in \mathrm{A}$. 


\section{Theorem 2.4}

A subset $A$ of $(Z, K)$ is semi-open if and only if $2 n-1$ or $2 n+1 \in A$ whenever $2 n \in A$.

Proof Necessity. Let $A \subseteq Z$ be semi-open and $2 n \in A$. Suppose $2 n-1$ and $2 n+1 \notin A$. Then

$\operatorname{int}(\mathrm{A}) \cap\{2 \mathrm{n}-1,2 \mathrm{n}, 2 \mathrm{n}+1\}=\phi$. This implies $\operatorname{int}(\mathrm{A}) \subseteq \mathrm{G}^{\mathrm{c}}$ where $G=\{2 n-1,2 n, 2 n+1\}$ is open. This implies $\operatorname{cl}(\operatorname{int}(A))$ $\subseteq \mathrm{G}^{\mathrm{c}}$ and therefore $2 \mathrm{n} \notin \mathrm{cl}(\operatorname{int}(\mathrm{A}))$ or

A $\not \subset \operatorname{cl}(\operatorname{int}(\mathrm{A}))$, a contradiction.

Sufficiency. To prove that $\mathrm{A} \subseteq \operatorname{cl}(\operatorname{int}(\mathrm{A}))$. Let $\mathrm{x} \in \mathrm{A}$. Case 1. $x=2 m+1$. Then $x \in \operatorname{int}(A)$ and therefore $x \in \operatorname{cl}(\operatorname{int}(A))$. Case 2 . $x=2 \mathrm{~m}$. Then $2 \mathrm{~m}-1$ or $2 \mathrm{~m}+1 \in \mathrm{A}$. This implies $2 \mathrm{~m}-1$ or $2 \mathrm{~m}+1 \in \operatorname{int}(\mathrm{A})$ and therefore $2 \mathrm{~m} \in \operatorname{cl}(\{2 \mathrm{~m}-1\}) \subseteq$ $\operatorname{cl}(\operatorname{int}(\mathrm{A}))$ or $2 \mathrm{~m} \in \operatorname{cl}(\{2 \mathrm{~m}+1\}) \subseteq \operatorname{cl}(\operatorname{int}(\mathrm{A}))$.

Using the characterization of the semi-closed subsets of $(\mathrm{Z}$, $\kappa)$, it can be proved that $(Z, K)$ is semi-regular and seminormal.

\section{Theorem 2.5}

$(\mathrm{Z}, \boldsymbol{K})$ is semi-regular.

Proof Let A be a semi-closed subset of $(\mathrm{Z}, \boldsymbol{\kappa})$ and $\mathrm{x} \notin \mathrm{A}$. Case $1 . x=2 n$. Since $x=2 n \notin A$, by Theorem 2.3, 2n-1 or $2 n+1 \notin A$. Let $U=\{2 n-1,2 n\}$ if $2 n-1 \notin A$ and $U=\{2 n, 2 n+$ $1\}$ if $2 n+1 \notin A$. Let $V=Z$ - U. Case $2 . x=2 n+1$. Let $U=\{2 n$ $+1\}$ and $V=Z-U$. In each case $U$ and $V$ are disjoint semiopen sets such that $\mathrm{x} \in \mathrm{U}$ and $\mathrm{A} \subseteq \mathrm{V}$. Hence $(\mathrm{Z}, \boldsymbol{K})$ is semi-regular.

\section{Theorem 2.6}

$(\mathrm{Z}, \boldsymbol{K})$ is semi-normal.

Proof Let $\mathrm{A}$ and $\mathrm{B}$ be disjoint semi-closed subsets of $(\mathrm{Z}$, $\kappa)$. Let $A=O_{1} \cup E_{1}$ and $B=O_{2} \cup E_{2}$ where $O_{1}$ and $O_{2}$ are subsets of $2 Z+1$ and $E_{1}$ and $E_{2}$ are subsets of $2 Z$. Let us form the semi-open sets $U$ and $V$ as follows. Let $2 n \in E_{1}$. Then $2 \mathrm{n} \notin \mathrm{E}_{2}$ and therefore $2 \mathrm{n} \notin \mathrm{B}$. Since $\mathrm{B}$ is semi-closed $2 \mathrm{n}-1$ or $2 \mathrm{n}+1 \notin \mathrm{B}$. Let $\mathrm{D}_{1}=\bigcup_{2 n \in E_{1}, x=2 n \pm 1, x \notin B}\{2 n, x\}$ and $\mathrm{U}$ $=\mathrm{O}_{1} \cup \mathrm{D}_{1}$. Similarly let $\mathrm{V}=\mathrm{O}_{2} \cup \mathrm{D}_{2}$ where

$\mathrm{D} 2=\bigcup_{2 m \in E_{2}, x=2 m \pm 1, x \notin A}\{2 m, x\}$. Then $\mathrm{U}$ and $\mathrm{V}$ are semiopen subsets of $(\mathrm{Z}, \boldsymbol{K})$ containing $\mathrm{A}$ and $\mathrm{B}$ respectively. Also $\mathrm{U} \cap \mathrm{V}=\phi$.

Now some more separation properties of $(\mathrm{Z}, \boldsymbol{\kappa})$.

Let us recall the following definitions.

\section{Definition 2.7}

A subset $\mathrm{A}$ of a topological space $(\mathrm{X}, \tau)$ is called

i. generalized closed (briefly g-closed) [16] if

$\operatorname{cl}(\mathrm{A}) \subseteq \mathrm{U}$ whenever $\mathrm{A} \subseteq \mathrm{U}$ and $\mathrm{U}$ is open in $\mathrm{X}$. ii. semi-generalized closed (briefly sg-closed) [3] if $\operatorname{scl}(\mathrm{A}) \subseteq \mathrm{U}$ whenever $\mathrm{A} \subseteq \mathrm{U}$ and $\mathrm{U}$ is semi-open in $\mathrm{X}$.

iii. generalized semi-closed (briefly gs-closed) [3] if $\operatorname{scl}(\mathrm{A}) \subseteq$ $\mathrm{U}$ whenever $\mathrm{A} \subseteq \mathrm{U}$ and $\mathrm{U}$ is open in $\mathrm{X}$.

iv. $\quad \alpha$-generalized closed (briefly $\alpha$ g-closed) [19] if $\alpha \operatorname{cl}(\mathrm{A})$ $\subseteq \mathrm{U}$ whenever $\mathrm{A} \subseteq \mathrm{U}$ and $\mathrm{U}$ is open in $\mathrm{X}$.

v. generalized $\alpha$-closed (briefly g $\alpha$-closed) [19] if $\alpha \operatorname{cl}(\mathrm{A})$ $\subseteq \mathrm{U}$ whenever $\mathrm{A} \subseteq \mathrm{U}$ and $\mathrm{U}$ is $\alpha$-open in $\mathrm{X}$.

vi. $\quad \omega$-closed or $\hat{g}$-closed [24] if $\operatorname{cl}(\mathrm{A}) \subseteq \mathrm{U}$ whenever $\mathrm{A} \subseteq \mathrm{U}$ and $\mathrm{U}$ is semi-open in $\mathrm{X}$.

Since any singleton subset of $(\mathrm{Z}, \boldsymbol{\kappa})$ is open or closed, $(\mathrm{Z}$, $\kappa)$ is $T_{1 / 2}$ [7]. Therefore the class of g-open sets $=$ the class of open sets in $(Z, \mathcal{K})$. Hence from Definition 3.1, it follows that, the class of $\omega$-closed sets $=$ the class of closed sets.

Since $(Z, \kappa)$ is $T_{3 / 4}$ and $T_{3 / 4}=T_{g s}+$ semi $T_{1}[4],(Z, \kappa)$ is also Tg. Hence in $(Z, K)$, the class of gs-open sets $=$ the class of sg-open sets $=$ the class of semi-open sets since $(Z$, $\kappa)$ is semi- $T_{1 / 2}$.

\section{Definition 2.8}

A subset A of a topological space (X, $\tau$ ) is called $\alpha-\hat{g}$ closed (briefly $\alpha \hat{g}$-closed) [1], if $\alpha \operatorname{cl}(\mathrm{A}) \subseteq \mathrm{U}$ whenever $\mathrm{A} \subseteq \mathrm{U}$ and $\mathrm{U}$ is $\hat{g}$-open Since $\hat{g}$-open sets in $(\mathrm{Z}, \boldsymbol{\kappa})$ are open sets, a subset $\mathrm{A}$ of $\mathrm{Z}$ is $\alpha \hat{g}$-closed if $\alpha \operatorname{cl}(\mathrm{A}) \subseteq \mathrm{U}$ whenever $\mathrm{A} \subseteq \mathrm{U}$ and $\mathrm{U}$ is open in $\mathrm{Z}$. That is the class of $\alpha$ $\hat{g}$-closed sets in $(\mathrm{Z}, \boldsymbol{\kappa})=$ the class of $\alpha$ g-closed sets in $(\mathrm{Z}, \boldsymbol{\kappa}) . \operatorname{In}(\mathrm{Z}, \boldsymbol{\kappa})$,

$\mathrm{PO}(\mathrm{Z}, \kappa)=\kappa=\alpha \mathrm{O}(\mathrm{Z}, \kappa)$.

Hence the class of $\alpha \hat{g}$-closed sets in (Z, $\kappa)$

$=$ the class of $\alpha$ g-closed sets in $(\mathrm{Z}, \kappa)$

$=$ the class of $g$-closed sets in $(\mathrm{Z}, \boldsymbol{\kappa})$

$=$ the class of closed sets in $(\mathrm{Z}, \boldsymbol{\kappa})$, since $(\mathrm{Z}, \boldsymbol{\kappa})$ is $\mathrm{T}_{1 / 2}$.

Also the class of g $\alpha$-closed sets in $(\mathrm{Z}, \kappa)$

$=$ the class of closed sets in $(Z, K)$.

\section{Definition 2.9}

A topological space (X, $\tau$ ) is called $T_{\alpha \hat{g}}$-space if every $\alpha$ $\hat{g}$-closed set is $\alpha$-closed.

Since $\alpha$-closed sets in $(\mathrm{Z}, \boldsymbol{K})$ are the closed sets in $(\mathrm{Z}, \boldsymbol{\kappa})$, $(\mathrm{Z}, \boldsymbol{K})$ is a $T_{\alpha \hat{g}}$-space.

\section{Definition 2.10}

A topological space $(\mathrm{X}, \tau)$ is called a $\mathrm{T}_{\mathrm{b}}$-space if every gsclosed set in $\mathrm{X}$ is closed. 
$(Z, K)$ is not a $T_{b}$-space. The set $A=\{2 n-1,2 n\}$ is semiclosed and therefore gs-closed in $(\mathrm{Z}, \mathcal{K})$. But A is not closed in $(\mathrm{Z}, \boldsymbol{K})$.

\section{Definition 2.11}

A topological space $(\mathrm{X}, \tau)$ is called a $\alpha \mathrm{T}_{\mathrm{b}}$-space if every $\alpha$ g-closed set in $\mathrm{X}$ is closed.

$(\mathrm{Z}, \kappa)$ is a $\alpha \mathrm{T}_{\mathrm{b}}$-space.

\section{REFERENCES}

[1] M.E. Abd El-Monsef, S. Rose Mary and M. Lellis Thivagar, 2007, $\alpha \hat{g}$-closed sets in topological spaces, Assiut Univ. J. of Mathematics and Computer Science,36(1)43-51.

[2] S.P. Arya and T. Nour, 1990, Characterizations of snormal spaces, Indian J. Pure Appl. Math., 21(8), 717719.

[3] P. Bhattacharya and B.K. Lahiri, 1987, Semi-generalised closed sets in topology, Indian J. Math., 29, 375-382.

[4] J. Dontchev and M. Ganster, 1996, On $\delta$ generalized closed sets and $\mathrm{T}_{3 / 4}$-spaces, Mem. Fac. Sci. Kochi Univ.(math),17,15-42.

[5] C. Dorsett, 1982, Semi-regular spaces, Soochow J. Math.8, 45-53.

[6] C. Dorsett, 1985, Semi-normal spaces, Kyungpook Math. J25, 173-180.

[7] W. Dunham, 1977, $\mathrm{T}_{1 / 2}$-spaces, Kyungpook Math. J. 17,161-169.

[8] M. Fujimoto, S. Takigava, J. Dontchev, T. Noiri and H. Maki, 2006, The topological structures and groups of digital n-spaces, Kochi J. Math., 1, 31-55.

[9] T. Fukutake, P. Sundaram and M. Sheik John, 2002, $\omega$ ciosed sets, $\omega$-open sets and $\omega$-continuity in bitopological spaces, Bull. Fukuoka Univ. Ed. Part III, $51,1-9$.

[10] E.D. Khalimsky, 1970, Applications of connected ordered topological spaces in topology, Conference of math. departments of Povolsia.
[11] E.D. Khalimsky, 1987, Topologicals structures in computer sciences, J . Appl. Math., Simulation, 1(1) , 2540.

[12] E.D. Khalimsky, R. Kopperman and P. R. Meyer, 1990, Computer graphics and connected topologies on finite ordered sets, Topology Appl., 36,1-17.

[13] T. Y. Kong, R. Kopperman and P. R. Meyer, 1991, A topologicai approach to digital topology, Amer. Math. Monthly, 98, 901- 917.

[14] V. Kovalevsky and R. Kopperman, 1994, Some topologybased image processing algorithms, Annals of the New York Academy of Sciences, Papers on General Topology and its Applications, 728, 174-182.

[15] N. Levine, 1963, Semi-open sets and semi-continuity in topological spaces, Amer. Math. Monthly 70, 36-41.

[16] N. Levine, 1970, Generalised closed sets in topology, Rend. circ. Mat. Palermo, 19, 89-96.

[17] S. Maheshwari and R. Prasada, 1978, On s-normai spaces, Bull. Math. Soc. Sci. R.S. Roumanie, 22(70) ( 1), 27-29.

[18] A.S. Mashhour, M.E. Abd El-Monsef and S.N. El Deeb, 1982, On pre continuous and weak pre continuous mappings, Proc. Math. Phys. Soc. Egypt., 53, 47-53.

[19] H. Maki, R. Devi and K. Balachandran, 1994, Associated topologies of generalized $\alpha$-closed sets and $\alpha$ generalized closed sets, Mem. Fac. Sci. Kochi Univ.Ser.A.Math.15, 51-63.

[20] S.I. Nada, 2004, Semi-open and semi-closed sets in digital toprological spaces, Commun. Fac. Sci. Uniu. Ank. Series A1, 53(1), 1-6.

[21] O. Njastad, 1965, On some classes of nearly open sets, Pacific J.Math.15, 961- 970.

[22] M. Sheik John, 2000, A study on generalizations of closed sets and continuous maps in topoiogical spaces, Ph.D. Thesis, Bharathiar University, Coimbatore, India.

[23] P. Sundaram and M. Sheik John, 1995, Weakly closed sets weak continuous maps in topological spaces, Proc.82 nd Indian Sci. Cong. Calcutta, 49.

[24] P. Sundaram ancl M. Sheik John, 2000, On $\omega$-closed sets in topology, Acta ciencia Indica, 26M (4), 389-392. 